\title{
ANALISIS USAHATANI SAGU (Metroxylon sagu Rottb.) DI KABUPATEN LUWU UTARA, SULAWESI SELATAN
}

\author{
The analysis of Sago Farmin (Metroxylon sagu Rottb.) \\ in North Luwu District, South Sulawesi
}

\section{Alfred P. Manambangtua}

Balai Penelitian Tanaman Palma

*Kontak penulis: alfredpahala@gmail.com

\begin{abstract}
Sago is a palm plant that can be used as a pith on the stems into flour. Sago has potential as an alternative food source because it contains a high carbohydrate content. Sago plants have many advantages over other carbohydrate-producing plants, because they can be harvested at any time regardless of the season. The results showed that. Sago farmers in North Luwu District monthly income of Rp. 109.349,- and Rp. 1.312.186,- per year. Calculation Analysis of R / C Ratio of sago farmers in Nort Luwu is 4,14, under the condition if the value of $R / C$ Ratio $>1$ then the work done can be profitable and worth trying.
\end{abstract}

Keyword: sago, income, sago farmers

\section{Abstrak}

Sagu merupakan tanaman palma yang dapat dimanfaatkan empelur pada batangnya menjadi tepung. Sagu memiliki potensi sebagai sumber pangan alternatif karena mengandung kandungan karbohidrat yang tinggi. Tanaman sagu banyak memiliki keungulan dibanding tanaman penghasil karbohidrat lainnya, karena dapat dipanen kapan saja tanpa memperhatikan musim. Hasil penelitian menunjukan bahwa rata-rata pendapatan petani sagu di Kabupaten Luwu Utara adalah sebesar Rp. 109.349,-/bulan atau Rp. 1.312.186/tahun. Perhitungan R/C ratio petani sagu di Luwu Utara yaitu sebesar 4,14, dengan ketentuan jika nilai $\mathrm{R} / \mathrm{C}$ Ratio $>1$ maka usaha yang dilakukan dapat menguntungkan dan layak untuk diusahakan.

Kata kunci : sagu, pendapatan, petani sagu

Sitasi: Alfred P. Manambangtua, 2020. Analisis Usahatani Sagu (Metroxylon Sagu Rottb.) Di Kabupaten Luwu Utara, Sulawesi Selatan. JSEP 16 (1): 115 - 122.

\section{Pendahuluan}

Sagu merupakan tanaman palma yang dapat dimanfaatkan empelur pada batangnya menjadi tepung. Tepung sagu ini dapat dimanfaatkan untuk dibuat menjadi bahan baku pembuatan roti dan pangan tradisional lainnya berupa papeda, selain itu tepung sagu juga dapat diolah menjadi bahan baku berbagai industri dan sebagai bahan energi alternatif berupa bioetanol. (Ruhukail, 2012).

Sagu memiliki potensi sebagai sumber pangan alternatif karena mengandung kandungan karbohidrat yang tinggi, di sebagian daerah di Indonesia masyarakatnya mengkonsumsi sagu sebagai bahan makanan pokok selain beras. Tanaman sagu banyak memiliki keungulan dibanding tanaman penghasil karbohidrat lainnya, karena dapat dipanen kapan saja tanpa memperhatikan musim, terkena serangan 
hama dan penyakit resikonya kecil, dan dapat dilakukan panen berkelanjutan tanpa melakukan peremajaan karena sagu berkembang biak dengan anakan. (Bustaman, 2008)

Sagu biasanya tumbuh pada lahan yang tergenang dan juga lahan yang tidak tergenang asal kandungan air di dalam tanahnya tinggi, dapat tumbuh baik pada Ph tanah sangat masam sampai agak masak dan akan terhambat pertumbuhannya pada tanah yang ber $\mathrm{pH}$ basa. bisa tumbuh pada ketigian $0-700 \mathrm{dpl}$, namun untuk ketinggian yang terbaik tidak lebih dari $400 \mathrm{dpl}$. (Notohadiprawiro, el al. 2006). Untuk budidaya sagu, ada beberapa petani yang segaja menanam sagu walaupun dengan jarak yang tidak beraturan, namun pada umumnya sagu tumbuh secara liar berupa hutan sagu. untuk jumlah pohon yang bisa dipanen per hektarnya setiap tahunya berbeda-beda tergantung pada jenis dan daerah pertumbuhan tanaman sagu. (Timisela, 2006).

Kabupetan Luwu Utara merupakan sentra sagu yang ada di propinsi sulawesi selatan. pada tahun 2016 produksi sagu di luwu utara sebesar 1.938 ton dan luas areal sagu sebesar 1,789 Ha, merupakan kabupaten yang memiliki produksi dan luasan sagu tertinggi dibandingkan dengan kabupaten lain yang ada di Sulawesi Selatan. (Dirjenbun, 2017).

Berbagai jenis pangan yang berbahan baku sagu banyak diproduksi oleh masyarakat di Tana Luwu. Selain sebagai sumber pangan, sagu juga merupakan penopang sumber ekonomi keluarga dan menghidupi sebagian besar masyarakat yang berada didaerah pesisir. Kehidupan masyarakat di Tana Luwuk (Khususnya Luwu Utara) tidak dapat dipisahkan dari tanaman sagu (Mulyadi et al, 2017).

Sagu di Luwu Utara biasanya dimanfaatkan sebagai penganti beras dan panganan lainnya. Jenis makanan olahan dari sagu yang paling banyak digemari dan dikonsumsi rumah tangga adalah kapurung. Kapurung merupakan makanan khas yang berbahan dasar tepung sagu yang digulung dan dicampur di dalam sayuran berkuah. Kapurung biasanya disajikan hampir tiap hari dan juga sering disajikan pada acara pernikahan, aqiqah, acara adat dan acara lainnya sebagai makanan pelengkap saat berkumpulnya keluarga (Ernawati et al, 2018). Selain kapurung, makanan lain yang berbahan dasar tepung sagu yang disukai masyarakat Luwu Utara adalah dange. Dange menurut masyarakat di daerah pesisir lebih mengenyangkan dibandingkan kapurung (Hayati, et al, 2014). Dange (ruji) merupakan makanan siap saji yang terbuat dari sagu yang berbentuk kotak tipis yang selalu disajikan bersama makanan khas lainnya (Fidyansari, 2017).

Pada saat ini usaha petani sagu di Luwu Utara hanya dilakukan petani sebagai usaha sampingan untuk menambah penghasilan, namun petani belum mengetahui apakah usaha pertanian sagu ini bisa memberikan keuntungan bagi mereka. sehingga penulis ingin mengetahui apakah usaha pertanian sagu di Kabupaten Luwu Utara bisa memberikan keuntungan.

\section{Metode Penelitian}

\section{Tempat dan Waktu}

Penelitian dilakukan di Kabupaten Luwu Utara, pada Kecamatan Malangkey Barat yang merupakan salah satu sentra sagu yang ada di Propinsi Sulawesi Selatan. Daerah sampel ditentukan secara sengaja (purposive). Peneitian ini dilakukan dengan mengumpulkan data primer dan sekunder. 


\section{Metode Pengumpulan Data}

Dalam penelitian ini dilakukan pengumulan data primer dan sekunder. Data primer diperoleh melalui wawancara menggunakan kuisioner terhadap 60 petani sagu dan pengamatan langsung di lapangan. Untuk data sekunder diambil dari dokumen-dokumen penunjang lainnya.

\section{Alat dan Bahan}

Alat yang digunakan berupa alat tulis untuk mencatat hasil quisioner, perangkat komputer untuk megolah data. Bahan yang digunakan adalah quisioner yang digunakan untuk mengumpulkan data.

\section{Analisis Data}

Analisis data yang digunakan dalam penelitian dengan rumus ( Shinta, 2011) sebagai berikut :

1) Penerimaan Usaha Tani

$$
\text { TR }=\text { Py. } Y
$$

Keterangan :

$$
\begin{array}{ll}
\mathrm{TR} & =\text { Total Penerimaan } \\
\mathrm{Py} & =\text { Harga Produk } \\
\mathrm{Y} & =\text { Produksi yang diperoleh }
\end{array}
$$

2) Biaya Produksi Usaha Tani

$$
\mathbf{T C}=\mathbf{F C}+\mathbf{V C}
$$

Keterangan :

$$
\begin{array}{ll}
\text { TC } & =\text { Total Biaya Produksi } \\
\text { FC } & =\text { Biaya Tetap } \\
\text { VC } & =\text { Biaya tidak Tetap }
\end{array}
$$

3) Pendapatan Usaha Tani

$$
\mathbf{I}=\mathbf{T R} \text { - TC }
$$

Keterangan

$$
\begin{array}{ll}
\mathrm{I} & =\text { Pendapatan (Income) } \\
\mathrm{TR} & =\text { Total Penerimaan } \\
\mathrm{TC} & =\text { Total Biaya }
\end{array}
$$

4) Kelayakan Usaha Tani

Kelayakan usaha tani dihitung dengan Return Cost Ratio (R/C)

$\mathrm{R} / \mathrm{C}$

Keterangan :

$$
\begin{aligned}
& \mathrm{R} \quad=\text { Py } . \mathrm{Y}(\text { Revenue = Penerimaan usaha tani }) \\
& \mathrm{C}=\mathrm{FC}+\mathrm{VC}(\text { Cost }=\text { Biaya produksi usaha tani }) \\
& \text { Jika } \quad \mathrm{R} / \mathrm{C} \geq 1 \quad=\text { Maka Usaha Tani Layak diusahakan } \\
& \mathrm{R} / \mathrm{C}<1 \quad=\text { Maka Usaha Tani Tidak Layak diusahakan }
\end{aligned}
$$




\section{Hasil Dan Pembahasan}

\section{A. Lokasi Pertanian}

Luwu Utara merupakan kabupaten yang berada di Propinsi Sulawesi Selatan. Pada awalnya sebelum pemekaran, Luwu Utara berada di Kabupaten Luwu dengan wilayah meliputi : Wara, Larompong, Suli, Bajo, Bupon, Bastem, Walenrang (Batu sitanduk), Limbong, Sabbang, Malangke, Masamba, Bone-bone, Wotu, Mangkutana, Malili, Nuha. Kemudian dimekarkan menjadi Kota Palopo, Kabupaten Luwu, Kabupaten Luwu Utara dan Kabupaten Luwu Timur.

\section{B. Karakteristik Petani}

Faktor penting dalam usaha tani adalah keadaan petani yang gambarannya diperoleh dari karateristik petani.

Tabel 1.

Karakteristik Petani Sagu di Kab. Luwu Utara

\begin{tabular}{llcc}
\hline No & \multicolumn{1}{c}{ Keterangan } & Jumlah (Orang) & Persen (\%) \\
\hline 1 & Umur Petani & 0 & 0 \\
& $<15$ tahun & 44 & 73,33 \\
& $15-64$ tahun & 16 & 26,67
\end{tabular}

2 Tingkat Pendidikan

Tidak sekolah/Tidak tamat SD

$2 \quad 3,33$

SD

$29 \quad 48,33$

SLTP 15

25,00

SLTA

$12 \quad 20,00$

D3 - S1

23,33

3 Pengalaman Bertani

$\begin{array}{lcc}0-10 \text { tahun } & 8 & 13,33 \\ 11-20 \text { tahun } & 18 & 30,00 \\ 21-30 \text { tahun } & 10 & 16,67 \\ 31-40 \text { tahun } & 12 & 20,00 \\ 41 \text { ke atas } & 12 & 20,00\end{array}$

$4 \quad$ Pekerjaan Utama

$\begin{array}{lll}\text { Petani Sagu } & 3 & 5,00\end{array}$

$\begin{array}{lll}\text { Petani lain } & 29 & 48,33\end{array}$

Peternak $\quad 1 \quad 1,67$

$\begin{array}{lll}\text { Perikanan } & 13 & 21,67\end{array}$

Non Pertanian $14 \quad 23,33$

Sumber : Hasil Pengolahan Data Primer 2018

\section{Umur Petani}

Umur petani sangat berperan penting dalam kemampuan fisik bekerja, jika semakin tinggi umur petani setelah melewati batas umur tertentu, maka semakin 
berkurang kemampuan beprestasi sebagai tenaga kerja (Ruauw, 2011 dalam Manambangtua et al, 2018). Berdasarkan hasil penelitian diperoleh bahwa petani sagu di Luwu Utara berusia produktif yang itu kisaran 15 - 64 tahun (73,33 \%).

\section{Tingkat pendidikan}

Tingkat pendidikan petani akan mempengaruhi kemampuan dan pengetahuan petani dalam menerima dan menyerap suatu teknologi baru berupa inovasi dan ilmu pengetahuan dalam tujuan untuk meningkatkan suatu produktivitas serta mempengaruhi cara petani dalam mengambil keputusan saat memecahkan masalah yang dihadapi saat mengelola dan mengembangkan usaha taninya. (Sundari, 2011 ; Wijayanti, 2012).

Berdasarkan data yang diperoleh dari petani sampel dapat dilihat bahwa tingkat pendidikan petani sagu di Luwu Utara sebagian besar merupakan tamatan SD sebesar 48,33\%, tidak tamat SD atau tidak sekolah sebesar 3,3 \%, untuk tamatan SLTP dan SLTA sebesar 25 dan $20 \%$ dan terdapat juga petani sagu yang berpendidikan lebih tinggi sebesar 3,3 \%. hal ini dapat terlihat bahwa tingkat pendidikan petani sagu di Luwu Utara tidak terlalu rendah karena tamatan pendidikan yang lebih tinggi dari SD hampir berimbang. hal ini dapat disebabkan sudah adanya tingkat kesadaran pada masyarakat di Luwu Utara untuk melanjutkan pendidikan ketingkat yang lebih tinggi.

\section{Pengalaman Petani}

Pada hasil penelitian di dapat bahwa petani sagu di kabupaten luwu utara memiliki pengalaman bertani sagu pada kisaran 11- 20 tahun sebesar $30 \%$ dan masing-masing sebesar $20 \%$ untuk petani sagu yang berpengelaman kisaran 31-40 tahun dan 40 keatas. Petani dalam memperbaiki praktek dan mengembangkan usaha tani yang dikelolanya berdasarkan pengalaman yang diperolehnya, sehingga petani dengan pengalaman yang lebih memadai lebih efisien dan efektif dalam mengelola usaha taninya. Pengalaman juga memberi kemampuan bagi petani untuk mengorganisasi, melaksanakan serta mengevaluasi suatu proses produksi (Sundari, 2011). Berdasarkan lama pengalaman di Kabupaten Luwuk Utara ini, petani sagu cenderung mampu menghadapi permasalahan dalam pengelolaan dan pengembangan usaha taninya.

\section{Pekerjaan Utama}

Berdasarkan hasil penelitian, didapat bahwa hampir $95 \%$ petani sampel yang ada di Luwu Utara bertani sagu bukan merupakan pekerjaan utama mereka, karena selain sebagai petani sagu, mereka bekerja pada usaha tani lainya sebesar 48,33\% (hortikultura, jagung, palawija), ada bekerja di bidang perikanan 21, 67 \% (tambak ikan, nelayan), peternakan 1,67 \% dan beberapa bekerja di luar bidang pertanian sebanyak 23,33 \% (Guru, Ojek, buruh tani, pedagang, wiraswasta).

\section{Analisis Ekonomi}

\section{Biaya Usaha Petani Sagu}

Setiap melakukan suatu usaha tentunya memerlukan masukan ekonomi berupa biaya yang dapat diperkirakan dan dapat diukur baik dalam bentuk benda maupun jasa selama proses produksi berlangsung (Sundari, 2011). 
Biaya usaha tani dibedakan menjadi dua yaitu biaya tidak tetap (variabel) dan biaya tetap. Biaya tetap adalah biaya yang besarnya tidak bertambah seiring dengan pertambahan produksi yang akan dihasilkan, sedangkan biaya tidak tetap adalah biaya yang besar kecilnya dipengaruhi oleh volume produksi.

Tabel 2.

Biaya Pada Usaha Petani Sagu di Kabupetan Luwu Utara.

\begin{tabular}{l|l|c|c}
\hline No & Biaya & Nilai/Bulan (Rp) & Nilai/Tahun (Rp) \\
\hline 1 & Biaya Variabel & 19.310 & 231.714 \\
2 & Biaya Tetap & 15.556 & 186.667 \\
& Jumlah & $\mathbf{3 4 . 8 6 5}$ & $\mathbf{4 1 8 . 3 8 1}$ \\
\hline
\end{tabular}

Sumber : Hasil Pengolahan Data Primer 2018

Berdasarkan hasil analisis biaya didapat bahwa total biaya yang dikeluarkan oleh petani sagu di Kabupaten Luwu Utara selama satu bulan produksi adalah Rp 34.865,- dan biaya yang dikeluarkan selama satu tahun produksi sebesar Rp. 418.380,--.

\section{Penerimaan Petani Sagu}

Produksi dan harga yang berlaku mempengaruhi besar kecilnya penerimaan yang diperoleh dari suatu usaha tanu. Dalam melakukan usaha tani, petani berharap dapat meningkatkan penerimaan sehingga kebutuhan hidup sehari-hari dapat dipenuhi (Akram, 2017)

Tabel 3.

Penerimaan Usaha Petani Sagu di Kabupaten Luwu Utara

\begin{tabular}{c|c|c|c}
\hline No & Keterangan & $\begin{array}{c}\text { Rata-rata Penerimaan } \\
\text { /Bulan (Rp) }\end{array}$ & $\begin{array}{c}\text { Rata-rata Total } \\
\text { Penerimaan/Tahun (Rp) }\end{array}$ \\
\hline 1 & Petani Sagu & 144.214 & 1.730 .567 \\
\hline
\end{tabular}

Sumber : Hasil Pengolahan Data Primer 2018

Pada Tabel 3 terlihat bahwa rata-rata penerimaan per bulan petani sagu di Kabupaten Luwu Utara sebesar Rp. 144.214,- dan rata-rata penerimaan pertahun sebesar Rp 1.730.567,-

\section{Pendapatan Petani Sagu}

Besarnya pendapatan yang akan diperoleh petani dari suatu kegiatan usaha taninya tergantung pada bebera faktor yang mempengaruhi, seperti luas lahan, tingkat produksi dan efisiensi penggunaan tenaga kerja. (Akram, 2017)

Pendapatan yang diperoleh petani Sagu di Kabupaten Luwu Utara dapat dilihat pada Tabel 4. Pendapatan merupakan suatu hal yang sangat penting dalam menentukan laba atau rugi. Pendapatan merupakan selisih antara total penerimaan yang diperoleh dengan total biaya yang dikeluarkan selama proses produksi. 
Tabel 4.

Pendapatan Petani Sagu di Kabupaten Luwu Utara

\begin{tabular}{l|l|c|c}
\hline No & Keterangan & Nilai/Bulan (Rp) & Nilai/Tahun (Rp) \\
\hline 1 & Penerimaan & 144.214 & 1.730 .567 \\
2 & Biaya & 34.865 & 418.380 \\
& Pendapatan (Penerimaan - Biaya) & $\mathbf{1 0 9 . 3 4 9}$ & $\mathbf{1 . 3 1 2 . 1 8 6}$ \\
\hline
\end{tabular}

Sumber : Hasil Pengolahan Data Primer 2018

Dari Tabel 6 dapat dilihat bahwa pendapatan petani sagu di Kabupaten Luwu Utara sebesar Rp 59.639,- per bulan dan memperoleh pendapatan per tahunya sebesar Rp 1.312.186,-

\section{Analisis R/C Usaha Petani Sagu}

Menurut Hasibuan (2014) dalam Manambangtua et al (2018), R/C ratio adalah singkatan dari Return Cost Ratio, atau dikenal sebagai perbandingan (nisbah) antara penerimaan dan biaya. Secara teoritis dengan rasio $\mathrm{R} / \mathrm{C}=1$ artinya tidak untung dan tidak rugi, jika nilai $\mathrm{R} / \mathrm{C}>1$ usahatani yang dilakukan adalah layak sedangkan jika $\mathrm{R} / \mathrm{C}<1$ maka usahatani yang dilakukan tidak layak.

Tabel 5.

Analisis R/C Ratio Pada Usaha Petani Sagu di Kabupaten Luwu Utara

\begin{tabular}{l|l|r}
\hline No & Keterangan & Nilai/Bulan (Rp) \\
\hline 1 & Penerimaan & 144.214 \\
2 & Biaya & 34.865 \\
& R/C Ratio (Penerimaan/Biaya) & $\mathbf{4 , 1 4}$ \\
\hline
\end{tabular}

Sumber : Hasil Pengolahan Data Primer 2018

Berdasarkan perhitungan $\mathrm{R} / \mathrm{C}$ rasio pada usaha petani sagu di Kabupaten Luwu Utara sebesar 4,14, sehingga dapat disimpulkan bahwa usaha tani sagu menguntungkan dan layak untuk diusahakan, karena nilai $\mathrm{R} / \mathrm{C}$ rasionya lebih besar dari satu atau $\mathrm{R} / \mathrm{C}>1$.

\section{Kesimpulan}

Rata-rata pendapatan petani sagu di Kabupaten Luwu Utara adalah sebesar Rp. 109.349,-/bulan atau Rp. 1.312.186/tahun. Perhitungan R/C ratio petani sagu di Luwu Utara yaitu sebesar 4,14, dengan ketentuan jika nilai R/C Ratio $>1$ maka usaha yang dilakukan dapat menguntungkan dan layak untuk diusahakan.

\section{Daftar Pustaka}

Akram. 2017. Analisis Tingkat Pendapatan Petani Sagu di Kabupaten Luwu. 2017. [Skripsi]. Departemen ilmu Ekonomi. Fakultas Ekonomi dan Bisnis. Universitas Hasanuddin. Makasr. 
Bustaman, Sjahrul. 2008. Strategi Pengembangan Bio-etanol Berbasis Sagu di Maluku. Perspektif. 7(2) : 65 - 79.

Direktorat Jenderal Perkebunan (Dirjenbun). 2017. Statistik Perkebunan Indonesia 2016-2018 Sagu. Sekretariat Direktorat Jenderal Perkebunan. Direktorat Jenderal Perkebunan. Kementerian Pertanian.

Ernawati, Endah., Heliawaty., dan Pipi Diansari. 2018. Peranan Makanan Tradisional Berbahan Sagu Sebagai Alternatif Dalam Pemenuhan Gizi Masyarakat : Kasus Desa Laba, Kecamatan Masamba, Kabupaten Luwu Utara, Propinsi Sulawesi Selatan. Jurnal Sosial Ekonomi Pertanian 14 (1) : 31 - 40.

Fidyansari, Dharma dan Haerul J. 2017. Analisa Usaha Ruji (Dange) dan Tingkat Kesejahteraan Keluarga di Desa Waelawi Kecamatan Malangke Barat Kabupaten Luwu Utara. Jurnal Pertanian Berkelanjutan. 5 (2) : 1 - 12.

Hasibuan, Hotmaidah. 2014. Analisis Biaya Dan Pendapatan Usahatani Jagung Hibrida Panen Muda Dan Panen Tua Serta Faktor-Faktor Yang Mempengaruhi Pendapatan (Studi Kasus Di Nagari Sungai Talang Kecamatan Guguak Kabupaten Lima Puluh Kota). [Skripsi]. Fakultas Pertanian Universitas Muhammadiyah Sumatera Barat. Payakumbuh.

Hayati, Nur., Rini Purwanti., dan Abd. Kadir W. 2014. Preferensi Masyarakat Terhadap Makanan Berbahan Sagu (Metroxylon sagu Rottb) Sebagai Alternatif Sumber Karbohidrat di Kabupaten Luwu dan Luwu Utara Sulawesi Selatan. Jurnal Penelitian Sosial dan Ekonomi Kehutanan. 11 (1) : 82 - 90.

Manambangtua, A. P,. Ronald TP. Hutapea., dan Jerry Wungkana. 2018. Analisis Usaha Tani Aren (Arengan pinnata Merr) Di Kota Tomohon, Sulawesi Utara. Jurnal Sosial Ekonomi Pertanian. 14 (1) : 85 - 92.

Timisela, Natelda R., 2006. Analisis Usaha Sagu Rumahtangga dan Pemasarannya. Jurnal Agroforestri. I (3) : 57 - 64 .

Bustaman, Sjahrul. 2008. Strategi Pengembangan Bioetanol Berbasis Sagu di Maluku. Perspektif. 7(2) : $65-79$.

Sundari, Mei Tri. 2011. Analisis Biaya dan Pendapatan Usaha Tani Wortel Di Kabupaten Karanganyar. Sepa. 7(2).

Mulyadi, Rosady., Dorothe Agnes Rampisela., Suryani As'ad., Muh. Taufiqurrahman, Rinaldi Sjahril., Makkarennu., Abdul Rahman Nur., Dwi Ratnasari., Ratna Maruddin., Andi P. Metaragakusuma. 2017. Studi Awal Pengembangan Sainsteknopark Sagu di Tana Luwu. Prosiding Temu Ilmiah Ikatan Peneliti Lingkungan Binaan Indonesia (IPLBI). 6 : 061 - 064.

Notohadiprawiro, Tejoyuwono., dan Julius E. Louhenapessy. 2006. Potensi Sagu Dalam Penganekaragaman Bahan Pangan Ditunjau dari Persyaratan Lahan. Repro. Ilmu Tanah Universitas Gadjah Mada.

Ruhukail, Novita L. 2012. Karakteristik Petani Sagu dan Keragaman Serta Manfaat Ekonomi Sagu Bagi Masyarakat Dusun Waipaliti Desa Hitu Kecamatan Leihitu Kabupetan Maluku Tengah. Jurnal Agroforestri. 7 (1) : 65 - 72.

Wijayanti, T., 2012. Analisis Pendapatan Usaha Tani Kelapa Sawit di Desa Makmur Jaya, Kecamatan Kongbeng, Kabupaten Kutai Timur. Media Sains. 4 (2). 